\title{
GATM, the human ortholog of the mouse imprinted Gatm gene, escapes genomic imprinting in placenta
}

\author{
Toshinobu Miyamoto ${ }^{1}$, Kazuo Sengoku ${ }^{1}$, Hiroaki Hayashi ${ }^{1}$, Yoshihito Sasaki ${ }^{1}$, Yoshihiro Jinno ${ }^{2}$ \\ and Mutsuo Ishikawa ${ }^{1}$ \\ ${ }^{I}$ Asahikawa Medical College, Department of Obstetrics and Gynecology, Asahikawa, Hokkaido, Japan. \\ ${ }^{2}$ Ryukyu University School of Medicine, Department of Molecular Biology, Nishihara, Okinawa, Japan.
}

\begin{abstract}
The GATM gene encodes L-arginine:glycine amidinotransferase, which catalyzes the conversion of L-arginine into guanidinoacetate, the rate-limiting step in the synthesis of creatine. Since, deficiencies in creatine synthesis and transport lead to certain forms of mental retardation in human, the human GATM gene appears to be involved in brain development. Recently it has been demonstrated that the mouse Gatm is expressed during development and is imprinted with maternal expression in the placenta and yolk sac, but not in embryonic tissues. We investigated the imprinting status of the human GATM by analyzing its expression in four human placentas. GATM was biallelically expressed, thus suggesting that this gene escapes genomic imprinting in placentas, differently from what has been reported in mouse extra-embryonic tissues.
\end{abstract}

Key words: GATM gene, genomic imprinting, DNA polymorphism.

Received: January 23, 2004; Accepted: November 17, 2004.

The GATM gene encodes L-arginine: glycine amidinotransferase, which catalyzes the rate-limiting step in the synthesis of creatine, i.e., the conversion of Larginine into guanidinoacetate (Wyss and KaddurahDaouk, 2000). Phosphocreatine, the phosphorylated form of creatine, serves as a reservoir for high-energy phosphate in ATP synthesis and is, therefore, critically involved in maintaining the energy balance (Ellington, 2001). In the mouse, the Gatm gene is expressed during development and is imprinted, so the only maternal allele is expressed exclusively in the placenta and yolk sac, but not in embryonic tissues (Sandell et al., 2003). It maps to mouse chromosome 2 in a region not previously shown to contain imprinted genes. In humans, the GATM gene, located on chromosome 15, appears to be important for brain development, since deficiencies in creatine synthesis and transport have been implicated in certain forms of mental retardation (Bianchi et al., 2000; van der Knaap et al., 2000). Mutations in the GATM gene itself (Item et al., 2001), as well as in other genes required for the synthesis or transport of creatine (Carducci et al., 2000; Leuzzi et al., 2000; Salomons et al., 2001; Stockler et al., 1996), have been described in such cases. However, the imprinting status of

Send correspondence to Toshinobu Miyamoto. Department of Obstetrics and Gynecology, Asahikawa Medical College, Asahikawa, Midorigaokahigashi 2-1-1-1, Hokkaido, 078-8510, Japan. E-mail: toshim@asahikawa-med.ac.jp.
GATM is unknown. Human GATM cDNA was isolated in 1994 by Humm, and the nucleotide sequence is available from GenBank under accession number BC004141. This $2342 \mathrm{bp}$ cDNA spans an open reading frame from nucleotide 70 to 1341 , encoding a putative 423 -amino acid protein.

Herein we report an investigation on the imprinting status of the GATM gene in human placentas. To determine the allelic expression status of the human GATM gene, nucleotide polymorphisms in the transcribed region were used. Four single-nucleotide polymorphisms (SNPs) at position 1904 (T/G), 1941 (G/A), 2056 (C/T) and 2067 (C/A) have been previously identified in the 3'UTR region (NM-001482).

Twenty placentas from healthy Japanese volunteers were studied. Written informed consent was obtained in each case. The placentas, with 7 to 40 weeks of gestation, were washed with saline solution, rapidly frozen in liquid nitrogen, and ground to a powder. Part of the powdered tissue was used for obtaining DNA, using standard proteinase $\mathrm{K}$ and SDS treatment, phenol/chloroform extraction and ethanol precipitation. Three primers were constructed encompassing the target region, and PCR was performed with the primers GATMFFF1(5'-GGGCAAGGTTCATTCTC CTG-3') and GATMRR2 (5'-AAGGATGGGAACTGA TAGCG-3'). Then, semi-nested PCR was done with the primers GATMFFF2 (5'-AACAGGGGTCGTAAGCCTG 
G-3') and GATMRR2. PCR was carried out in a total volume of $25 \mu \mathrm{L}$, containing $50 \mathrm{ng}$ genomic DNA, 5 pmol of each primer, 1 XTaq polymerase buffer $\left(1.5 \mathrm{mM} \mathrm{MgCl}_{2}\right)$, and 0.25 units of Amplitaq DNA polymerase (Perkin Elmer, Foster City, U.S.A.), under the following conditions: initial denaturation at $95{ }^{\circ} \mathrm{C}$ for $150 \mathrm{~s}$, followed by 32 cycles of denaturation at $95{ }^{\circ} \mathrm{C}$ for $30 \mathrm{~s}$, annealing at $55^{\circ} \mathrm{C}$ for $90 \mathrm{~s}$, and extension at $72^{\circ} \mathrm{C}$ for $90 \mathrm{~s}$. Semi-nested PCR was carried out under the same conditions, but for only 20 cycles. DNA was also purified and amplified from maternal peripheral blood.

RNA was extracted with guanidinium thiocyanate followed by centrifugation in a caesium chloride gradient. Total RNA was treated with DNase I (Roche, Tokyo, Japan) at $37{ }^{\circ} \mathrm{C}$ for $30 \mathrm{~min}$ to prevent contamination. The cDNA was synthesized from total RNA, using a cDNA synthesis kit (Roche). RT-PCR was carried out with total RNA, under the same conditions as PCR with the genomic DNA. Negative controls without oligo (dT) primer or reverse transcriptase were used.

Sequencing was performed with the primer GATMFF2 (5'-GCAGCTTGAAATGTTGGTCC-3'), using an ABI PRISM 3100 Genetic Analyzer (PE Applied Biosystems, Foster City, CA).

Sequence analyses of the genomic DNA from the 20 placentas did not reveal either $\mathrm{T} / \mathrm{G}$ heterozygotes at position 1904 (1904 T/G) or at $2067 \mathrm{C} / \mathrm{A}$. Four samples were heterozygous for both $1941 \mathrm{G} / \mathrm{A}$ and $2056 \mathrm{C} / \mathrm{T}$ polymorphisms. Gestation ages were seven weeks (one placenta), eight weeks (two), and 13 weeks (one). The alleles carried by the mothers were determined.

To examine the allelic expression of the human GATM gene in these four informative cases, RT-PCR products were sequenced. Both alleles were detected, demonstrating that the genes of both parental alleles were expressed equally in these placentas. These data suggest that there is a difference in the imprinting status between the human GATM and the mouse Gatm genes in extra-embryonic tissues. A similar discrepancy has been reported in the human and mouse ASCL2 (HASH2)/Ascl2 (Mash2) gene (Miyamoto et al., 2002; Guillemot et al., 1995).

\section{Acknowledgments}

We thank Mr. S. Bayley for the reading of our manuscript. The present study was supported by a Grant-in-Aid for Scientific Research (n. 16390471 and n. 16790934) from the Ministry of Education, Culture, Sports, Science and Technology of Japan.

\section{References}

Bianchi MC, Tosetti M, Fornai F, Alessandri MG, Cipriani P, De Vito G and Canapicchi R (2000) Reversible brain creatine deficiency in two sisters with normal blood creatine level. Ann Neurol 47:511-513.

Carducci C, Leuzzi V, Carducci C, Prudente S, Mercuri L and Antonozzi I (2000) Two new severe mutations causing guanidinoacetate methyltransferase deficiency. Mol Genet Metab 71:633-638.

Ellington WR (2001) Evolution and physiological roles of phosphagen systems. Annu Rev Physiol 63:289-325.

Guillemot F, Caspary T, Tilghman SM, Copeland NG, Gilbert DJ, Jenkins NA, Anderson DJ, Joyner AL, Rossant J and Nagy A (1995) Genomic imprinting of Mash2, a mouse gene required for trophoblast development. Nat Genet 9:235-242.

Humm A, Huber R and Mann K (1994) The amino acid sequences of human and pig L-arginine:glycine amidinotransferase. FEBS Lett 339:101-107.

Item CB, Stockler-Ipsiroglu S, Stromberger C, Muhl A, Alessandri MG, Bianchi MC, Tosetti M, Fornai F and Cioni G (2001) Arginine:glycine amidinotrasferase deficiency: The third inborn error of creatine metabolism in humans. Am J Hum Genet 69:1127-1133.

Leuzzi V, Bianchi MC, Tosetti M, Carducci C, Cerquiglini CA, Cioni G and Antonozzi I (2000) Brain creatine depletion: Guanidinoacetate methyltransferase deficiency (improving with creatine supplementation). Neurology 55:1407-1409.

Miyamoto T, Hasuike S, Jinno Y, Soejima H, Yun K, Miura K, Ishikawa M and Niikawa N (2002) The human ASCL2 gene escaping genomic imprinting and its expression pattern. $\mathrm{J}$ Assist Reprod Genet 19:240-244.

Salomons GS, van Dooren SJ, Verhoeven NM, Cecil KM, Ball WS, Degrauw TJ and Jakobs C (2001) X-linked creatinetransporter gene (SLC6A8) defect: A new creatinedeficiency syndrome. Am J Hum Genet 68:1497-1500.

Sandell LL, Guan XJ, Ingram R and Tilghman SM (2003) Gatm, a creatine synthesis enzyme, is imprinted in mouse placenta. Proc Natl Acad Sci USA 100:4622-4627.

Stockler S, Isbrandt D, Hanefeld F, Schmidt B and von Figura K (1996) Guanidinoacetate methyltransferase deficiency: The first inborn error of creatine metabolism in man. Am J Hum Genet 58:914-922.

van der Knaap MS, Verhoeven NM, Maaswinkel-Mooij P, Pouwels PJ, Onkenhout W, Peeters EA, Stockler-Ipsiroglu S and Jakobs C (2000) Mental retardation and behavioral problems as presenting signs of a creatine synthesis defect. Ann Neurol 47:540-543.

Wyss M and Kaddurah-Daouk R (2000) Creatine and creatinine metabolism. Physiol Rev 80:1107-1213.

Associate Editor: Angela M. Vianna-Morgante 